\title{
Homonacionalismo e cidadania LGBT em tempos de neoliberalismo: dilemas e impasses às lutas por direitos sexuais no Brasil
}

Homonationalism and LGBT citizenship in times of neoliberalism: dilemmas and impasses of the struggle for sexual rights in Brazil

Bruna Andrade Irineu*

\begin{abstract}
Resumo - Neste texto analisamos as lutas pelo reconhecimento dos direitos sexuais de lésbicas, gays, bissexuais, travestis e transexuais (LGBT) no Brasil. Observando as demandas por cidadania e direitos humanos LGBT, refletindo sobre direitos, democracia e justiça a partir de autores como Marilena Chauí, Carlos Nelson Coutinho e Alysson Mascaro. Traçamos um panorama da inserção dos direitos sexuais na pauta global dos direitos humanos, retomando a história das conferências e pactos internacionais. Problematizamos os conceitos de cidadania e política social em tempos de neoliberalismo, apoiandonos em Potyara Pereira e utilizando os conceitos de "reconhecimento com justiça", "redistribuição socioeconômica" e "representação com paridade de participação" de Nancy Fraser. Desenvolvemos uma crítica ao homonacionalismo presente nas demandas por "cidadania LGBT", no Brasil, através das contribuições de Jasbir Puar, Sarah Schulmman e Ochy Curiel. Desta forma, acredita-se ser possível empenharmos uma estratégia anticapitalista que rompa com as determinações neoliberais e promova a livre expressão sexual e de gênero. Palavras-chave: homonacionalismo; LGBT; direitos humanos; cidadania; políticas públicas;
\end{abstract}

\begin{abstract}
In this paper we analyze the struggles for the recognition of sexual rights of lesbians, gays, bisexuals and transgenders (LGBT) in Brazil. Observing the claims of citizenship and human LGBT rights we meditate over rights, democracy and justice from authors Marilena Chauí, Carlos Nelson Coutinho and AlyssonMascaro. We trace an overview of the integration of sexual rights on the global human rights' agenda, retaking the history of conferences and international agreements. We problematize the concepts of citizenship and social policy in times of neoliberalism, relying on Potyara Pereira and using concepts of "recognition with justice"," socioeconomic redistribution"
\end{abstract}

\footnotetext{
* Assistente social e professora de Serviço Social da Universidade Federal do Tocantins (UFT), coordenadora do Núcleo de Estudos, Pesquisas e Extensão em Sexualidade, Corporalidades e Direitos e doutoranda do Programa de Pós-Graduação em Serviço Social (UFRJ). Correspondência: Universidade Federal do Tocantins - Av. Lourdes Solino, S/N, Setor Universitário, CEP: 77.000-000, Miracema/TO, E-mail: <brunairineu@gmail.com>.
} 
and "representation with parity of participation" from Nacy Fraser. We developed a critique of this homonationalism present in the demands for "LGBT citizenship" in Brazil through the contributions of JasbirPuar, Sarah Schulmman and OchyCuriel. We believe it to be possible to engage an anti-capitalist strategy to break with the neoliberal determinations and promote free sexual and gender expression.

Keywords: homonationalism; LGBT; human rights; citizenship; public policy.

\section{Introdução}

É nosso interesse, neste artigo, analisar os processos que têm envolvido as lutas pelo reconhecimento dos direitos sexuais de lésbicas, gays, bissexuais, travestis e transexuais (LGBT). Ao tratar sobre as lutas e demandas por cidadania e direitos humanos desta população, torna-se necessário refletir sobre democracia e justiça no contexto brasileiro.

As lutas envolvendo gênero e sexualidade se instituem como movimento social organizado com o movimento feminista, no final do século XIX, no Ocidente, ampliando-se com a emergência do movimento homossexual na década de 1960. Estes movimentos questionaram a opressão e a subordinação das mulheres, confrontaram os modelos de família e o padrão de sexualidade, bem como instituíram uma "política do corpo" com capacidade de tensionar a biologização do sexo e o binarismo de gênero'.

A formação sócio-histórica e cultural da nação brasileira é marcada pelo poder oligárquico, por patrimonialismos, pelo clientelismo, pelo pânico à mestiçagem, envolto no racismo e no desejo pela branquitude, e pelo estabelecimento de um modelo familiar que delineou um padrão de masculinidade e (hetero)sexualidade, ancorado na dominação das mulheres (CARVALHO, 2008; MISCKOLCI, 2012). Essas características das relações sociais no Brasil também estão imbricadas em uma lógica de subalternização da sociedade civil em oposição à hipervalorização do Estado, o que Carvalho (2008) nomeou de estadadania. A excessiva valorização do Poder Executivo é apontada pelo autor como um fator significativo para a debilidade da democracia brasileira.

Em consonância, Chauí (2007), ao retomar os processos de formação de nosso país, revela o autoritarismo do Estado a partir do indicativo de negligenciamento e corrosão da democracia. O próprio Estado tornase, assim, o maior perpetuador da violência. Para a autora, as raízes deste autoritarismo se localizam no liberalismo, que emerge através destas lacunas da democracia, perpassando-a. Assim, as práticas sociais, políticas e eco-

\footnotetext{
${ }_{1}^{1}$ Normas de gênero que postulam padrões antagônicos para masculino e feminino, promovendo uma sequência na qual sexo-gênero-desejo se conectam em uma dinâmica de reiteração do sexo biológico como um destino que presumirá exercício do desejo limitado ao exercício da heterossexualidade (BUTLER, 2008).
} 


\section{ReVistg all paUtg}

\} HOMONACIONALISMO E CIDADANIA LGBT - IRINEU, B. A. \}

nômicas são marcadas por relações de privilégio, despotismo e clientelismo, incapazes de reconhecer os direitos humanos "nem em seus aspectos de igualdade jurídica.

Portanto, a violência do Estado, sendo superior à do indivíduo, abre um grande espaço para a violação dos direitos humanos. Isto ocasiona, também, o que lamamoto (2009) chamou de radicalização da questão social, que se traduz pela expressão contraditória das relações de produção e reprodução social no capitalismo. Isto envolve a constante exclusão das classes subalternas dos processos decisórios de poder e a criminalização das manifestações e dos movimentos sociais que criticam a ordem social vigente.

Ainda para lamamoto (2009, p. 123), a questão social tem uma raiz comum que correlaciona o fato de a produção social tornar-se cada vez mais coletiva enquanto o trabalho fica mais amplamente social, ao passo que a apropriação dos seus frutos permanece privada e monopolizada pela elite burguesa. A sua radicalização agrava a exploração e as desigualdades sociais, segregando as classes subalternas que não conseguem se inserir no mercado. À essa classe, "as alternativas que se lhes restam, na ótica oficial, são a violência e a solidariedade".

Todavia, é necessário ressaltar a resistência à exploração e à dominação, enquanto face politizada da "questão social", que se expressa no processo de organização das lutas sociais. Essa politização se dá em torno da ampliação da democracia e da cidadania, e é percebida por Coutinho (1997) como elemento que entra em choque com o ideário do sistema capitalista. Esse embate reforça a crítica que Mascaro (2013, p. 84) faz ao senso comum atual, que costuma vincular capitalismo à democracia. Retomando momentos da Grécia e de Atenas durante o modo de produção escravista e de sociedades capitalistas, este autor aponta que não havia democracia, como nas ditaduras instauradas na América Latina. Assim, em sociedades capitalistas, a democracia acaba sendo "mais exceção, do que regra".

Mascaro (2013, p. 85) argumenta que, no capitalismo, a forma política democrática está imbricada à forma jurídica, o que denota sua limitação. "Os agentes econômicos são tornados sujeitos de direitos e, como extensão dessa subjetividade para o plano político, cidadãos." Assim, a ação política é norteada pela liberdade de negociação/mercado, pela igualdade formal e propriedade privada. Democracia estaria condicionada, nas sociedades contemporâneas, à forma política estatal que vincula o "plano eleitoral e o plano constitucional e dá garantia da subjetividade jurídica" necessária à reprodução do capital, reforçando o direito como lócus fundamental da vida política. (MASCARO, 2013, p. 85).

Neste sentido, a democracia, ancorada no direito e na sociabilidade do capital, representa um espaço de liberdade deliberativa (pela possibilidade do sufrágio universal) e também de interdição às lutas sociais 


\section{hevista pll pavtg}

\} HOMONACIONALISMO E CIDADANIA LGBT - IRINEU, B. A. \}

(pelo bloqueio das lutas que não estejam previstas em termos jurídicos exatos). Isto gera uma sensação falaciosa - ou liberal - de democracia e cidadania (MASCARO, 2013; COUTINHO, 1997).

Sob o prisma desta crítica, pretende-se abordar, neste texto, o percurso para o reconhecimento dos direitos sexuais, no campo dos direitos humanos, e a configuração das lutas sociais LGBT no contexto brasileiro. Observa-se um avanço na inserção das demandas LGBT no âmbito das políticas públicas. Ao mesmo tempo, mostra-se a ineficácia destas respostas governamentais frente aos altos índices de violência letal a essa população, após os dez anos de lançamento do Programa Brasil sem Homofobia (BSH).

Articulam-se, neste cenário, os constantes retrocessos das pautas por reconhecimento da diversidade sexual devido ao recrudescimento dos grupos conservadores, especialmente no Legislativo. Como forma de ilustrar essa conjuntura, retoma-se episódios de conquista e recuo das pautas LGBT. Ao final, propõe-se uma conclusão assentada na crítica ao homonacionalismo.

\section{Um panorama da inserção dos direitos sexuais na pauta global dos direitos humanos}

Os direitos humanos têm seu nascimento nas lutas burguesas pela queda do absolutismo feudal, dos privilégios da nobreza e do clero, no final do século XVIII. Forti (2012, p. 274) considera não ser possível negar que há avanços na proposta destas lutas, decorrentes da "perspectiva de autonomia, ou seja, das leis como produto da razão humana, se comparada à lógica da heteronomia - preponderante no mundo feudal - e da possibilidade de Direitos Humanos (civis e políticos)".

Todavia, é importante lembrar que, embora seja considerada o marco dos direitos humanos, a Revolução Francesa conforma seu legado a uma perspectiva liberal. Inspirada em um direito "natural", que incorre numa noção individualista e a-histórica da humanidade, reforçou uma concepção de ser humano eurocêntrica, branca e masculinista. Determinou o domínio de uma elite a partir do estabelecimento da propriedade privada e da igualdade civil (perante a lei), assegurando a liberdade individual, mas não de forma universal. Assim, "a instituição do binômio legal - igualdade/liberdade - permitiu que emergisse a figura jurídica do 'sujeito de direitos', viabilizando a livre contratação, imprescindível à sociedade capitalista." (FORTI, 2012, p. 275). Os argumentos apresentados por Forti (2012) reiteram o que já havíamos apontado na introdução, ao referirmo-nos sobre democracia e acompanhando Mascaro (2013).

Em outra perspectiva, Vieira $(2005$, p. 21) apontou que a transição do Estado Absolutista para o Estado de Direito, invertendo a "relação tradicional de direitos dos governantes e deveres dos súditos, agora o indivíduo 


\section{hevistg all paUtg}

\} HOMONACIONALISMO E CIDADANIA LGBT - IRINEU, B. A. \}

tem direitos, e o governo obriga-se a garanti-los". O autor afirma que a concepção jusnaturalista presente na Declaração Francesa também foi incorporada na Declaração Universal dos Direitos do Homem, da Organização das Nações Unidas (ONU), em seu primeiro artigo "Todos os homens nascem livres e iguais em dignidade e direitos". Apoiando-se em Hanna Arendt, Vieira (2005, p. 21) reitera que a igualdade "não é um dado, é um construído". E afirma que "é com o nascimento do Estado de Direito que o ponto de vista do príncipe se transforma em ponto de vista do cidadão", passando a ter não só "direitos privados", mas também "direitos públicos".

Neste bojo, trataremos da internacionalização dos direitos humanos em sua constituição jurídica, que se institui no período posterior à Segunda Guerra Mundial, como "resposta às atrocidades e aos horrores cometidos durante o nazismo [...] que resultou no extermínio de 11 milhões de pessoas". (PIOVESAN, 2014, p.02).

Para Piovesan (2014), o maior marco do "processo de reconstrução dos direitos humanos" é a Declaração Universal dos Direitos Humanos de 1948, da ONU, cuja formulação foi arenosa, o que se expressou em seu caráter "generalizante" sobre vida, desigualdade e discriminação, por exemplo. Pereira (2011) afirma que os "direitos sociais" só foram inseridos na Declaração de 1948 por pressão do Terceiro Mundo e do mundo comunista. No entanto, a afirmação de Piovesan (2014) baseia-se no fato de que esta Declaração introduziria, na concepção contemporânea de direitos humanos, a universalidade e a indivisibilidade destes direitos.

Universalidade porque clama pela extensão universal dos direitos humanos, sob a crença de que a condição de pessoa é o requisito único para a dignidade e titularidade de direitos. Indivisibilidade porque a garantia dos direitos civis e políticos é condição para a observância dos direitos sociais, econômicos e culturais e vice-versa. Quando um deles é violado, os demais também o são. Os direitos humanos compõem assim uma unidade indivisível, interdependente e inter-relacionada. (PIOVESAN, 2014, p. 03).

Essa perspectiva universalista e indivisível, apresentada na Declaração de 1948, trouxe pressupostos generalizados acerca do direito à vida, integridade física, saúde, igualdade e não discriminação. Em um processo de democratização e ampliação da concepção internacional dos direitos humanos, os direitos reprodutivos e sexuais passam a ser considerados parte essencial destes direitos, o que configurou uma evolução histórica de conquistas e avanços em âmbito internacional. Porém, é importante ressaltar que esse percurso só se tornou viável pelo protagonismo dos movimentos feministas, e mais recentemente LGBT, em esferas nacionais e internacionais, que impulsionaram a construção dos direitos sexuais e reprodutivos, trazendo um aporte teórico para as experiências militantes pelos direitos das mulheres (PIOVESAN, 2014). 


\section{hevista pll pavtg}

\} HOMONACIONALISMO E CIDADANIA LGBT - IRINEU, B. A. \}

Tendo como ponto de partida o reconhecimento dos direitos reprodutivos como direitos humanos, com foco exclusivo na reprodução da mulher e condição feminina na sociedade, no ano de 1979 é promulgada a Convenção sobre a Eliminação de Todas as Formas de Discriminação contra a Mulher (CEDAW). Também citamos, neste esquadro, a centralidade da IV Conferência Mundial sobre a Mulher, realizada 1995 em Pequim, e da Conferência Internacional sobre População e Desenvolvimento, realizada no Cairo, em 1994. Culminando no Plano de Ação do Cairo, considerado um avanço na construção dos direitos reprodutivos, pois sinaliza o reconhecimento da existência de direitos sexuais, com destaque ao direito de exercer a sexualidade e a reprodução livre de violência, discriminações e coerções \% ainda que não compreendesse as questões de orientação sexual e identidade de gênero.

A inclusão dos direitos sexuais na pauta global de direitos humanos só foi consolidada a partir de propostas nas áreas referentes à população e à mulher, e não em um espaço específico " como uma conferência sobre direitos sexuais e reprodutivos. O que nos possibilita inferir que, sem minorizar a relevância dessa inserção, a compreensão de "direitos sexuais" tem, em sua origem, a correlação com o controle populacional e com a saúde reprodutiva da mulher, demonstrando os limites do processo inicial dessa inclusão.

A essas iniciativas internacionais soma-se, no âmbito da América Latina, a Convenção de Belém do Pará, realizada em 1994. Tinha, como foco, a violência contra a mulher e a responsabilidade dos estados no que se refere à tolerância à violência dos atos privados e à negligência por não promover políticas públicas para coibi-las.

A realização da $4^{a}$ Conferência Mundial da Mulher, na China, em 1995, produziu como documento a Plataforma de Ações de Pequim. Este instrumento seguiu as diretrizes da Conferência do Cairo no que se refere ao reconhecimento dos direitos sexuais e reprodutivos enquanto direitos humanos, propondo uma atenção maior ao acesso à informação, educação e saúde sexual. As duas conferências, Cairo e Pequim, trataram o aborto como questão de saúde pública e apontaram para uma revisão de legislações que criminalizam as mulheres que o praticam.

Corrêa (2006) considera que, apesar do fortalecimento do campo dos direitos sexuais nas duas conferências, este visível avanço dos "direitos sexuais" não acompanhou a questão da diversidade sexual. Ela aponta, ainda, que não houve menção explicita à orientação sexual nesses documentos. Mesmo na revisão de cinco anos da Conferência de Pequim, em 2000, não foi possível incluir no texto " em decorrência dos países islâmicos "as múltiplas formas de discriminação contra as mulheres no que se refere exclusivamente à orientação sexual. Consequentemente, não foi possível abordar as questões de identidade de gênero.

Em 2006, após grandes pressões do movimento feminista e LGBT no sistema das Nações Unidas, foram promulgados os "Princípios de Yogya- 


\section{ReVistg all paUtg}

\} HOMONACIONALISMO E CIDADANIA LGBT - IRINEU, B. A. \}

karta". Configuram-se em um documento que contém 29 princípios de amplo espectro de normas de direitos humanos e sua aplicação às questões de orientação sexual e identidade de gênero, principalmente em âmbito internacional. Como uma carta-reivindicação de direitos já estabelecidos, a construção dos Princípios Yogyakarta se baseou em uma lógica que buscou se distanciar de uma política de identidade fixa, alocando os sujeitos nos seus direitos para enfatizar as circunstâncias de violação e discriminação (CORRÊA, 2006).

Os direitos à igualdade e à não discriminação, no contexto regulatório dos instrumentos internacionais, têm se desenvolvido a partir das pressões da sociedade civil, de forma a abranger as novas realidades históricas. Retomando o cenário brasileiro, Rios (2006, p. 79) aponta que nosso país, além de ser signatário desses instrumentos internacionais, teria na própria Constituição Federal de 1988 a abertura para esse reconhecimento "seja pela quantidade de normas constitucionais expressas, definidoras de direitos e garantias individuais e coletivas, seja pela explícita cláusula de abertura a novos direitos humanos".

Embora a argumentação de Rios (2006) seja plausível como a perspectiva apresentada por Piovesan (2014), as lacunas entre direito, democracia e justiça, elucidadas por Mascaro (2013) e Forti (2012), configuram uma realidade de pouca efetividade na materialização dos direitos sexuais e reprodutivos. Além disso, também de um contínuo movimento de avanços e retrocessos no campo do direito à não discriminação por orientação sexual e identidade de gênero na esfera pública brasileira. Deste modo, para uma analítica no campo das lutas LGBT, torna-se necessário verificar as demandas por cidadania empreendidas pelo segmento e as respostas que o Estado tem dado através das políticas sociais.

\section{Refletindo sobre cidadania e política social em tempos de neoliberalismo}

Afirmando haver um fetiche na "condição de cidadão", Lessa (2006, p.10-11) alerta para o fato de que "em um Estado Liberal constituir-se-á uma cidadania liberal". Em outras palavras, o direito estabelecido pelo Estado não é suficiente para definir e assegurar a cidadania de todas as pessoas, tendo em vista que se inscreve numa determinada correlação de forças sociais. Apoiamo-nos aqui na noção de correlação de forças de Antônio Gramsci, na qual há um movimento de concessão - conquista, ou seja, pressão - consenso. (PASTORINI, 1997).

Ao referirmo-nos à cidadania, é inevitável citar a análise de T. H. Marshall, elaborada no final dos anos de 1940. Foi criticada por alguns segmentos dos movimentos feministas por utilizar uma perspectiva de universalidade, que desconsidera a dimensão de gênero e invisibiliza aqueles 


\section{hevista pll pavtg}

\} HOMONACIONALISMO E CIDADANIA LGBT - IRINEU, B. A. \}

que não se enquadram na ideia do "sujeito universal" - homem, branco, heterossexual e europeu. No entanto, foi muito aceita pelos movimentos filiados à perspectiva da social-democracia, nos anos 1950, 1960 e 1970 na Europa. Pereira (2011, p. 95) aponta que ele foi central no dimensionamento da compreensão da política social para além de "uma visão paternal ou contratual".

O estudo de Marshall considerou que a cidadania era composta de três grupos de direitos, desenvolvidos em épocas diferentes: direitos civis (século XVIII), direitos políticos (século XIX) e direitos sociais (XX). Na compreensão de Pereira (2011, p. 98), os direitos tradicionais (civis e políticos) e os novos direitos (sociais e econômicos) são discrepantes e incompatíveis entre si, posto que os primeiros servem à ideologia do individualismo e do livre mercado, enquanto os segundos impõem limites ao "despotismo do mercado" e ao "individualismo possessivo dos cidadãos".

Observando o processo de construção da cidadania no contexto nacional, cabe ressaltar que:

A cronologia e a lógica da seqüência descrita por Marshall foram invertidas no Brasil. Aqui, primeiro vieram os direitos sociais, implantados em período de supressão dos direitos políticos e de redução dos direitos civis por um ditador que se tornou popular. Depois vieram os direitos políticos, de maneira também bizarra. A maior expansão do direito do voto deu-se em outro período ditatorial, em que os órgãos de representação política foram transformados em peça decorativa do regime. Finalmente, ainda hoje muitos direitos civis, a base da seqüência de Marshall, continuam inacessíveis à maioria da população. A pirâmide dos direitos foi colocada de cabeça para baixo. (CARVALHO, 2008, p. 220).

O que o autor anuncia acima se correlaciona com o que Chauí $(2007,41)$ diz ao afirmar que "ter direitos é também ter poder". Um direito não é concedido, mas conquistado e cultivado, por ser uma forma de poder. Partindo daí, Chauí (2007, p. 41) descreve que, em nosso país, a maioria está "desprovida de poderes", o que demonstra que o processo político aqui envolve a "criação de direitos", ou seja, um processo de "constituição de poderes políticos". Para a autora, no Brasil, "o que temos é aquilo que ainda classicamente se chama à democracia formal. Mas é preciso uma democracia social e cultural".

Neste percurso, as políticas sociais vêm se configurando em respostas às demandas da sociedade civil por ampliação de direitos - ora legitimadoras da ordem estabelecida, ora potenciais instrumentos para emancipação política das "classes subalternas". Assim, as políticas sociais devem ser entendidas a partir da compreensão de sua inserção na lógica do capital, enquanto "expressão contraditória da realidade" (2007 p. 39). É necessário levar em conta também a "dimensão cultural" que está relacionada à política, 


\section{ReVistg all paUtg}

\} HOMONACIONALISMO E CIDADANIA LGBT - IRINEU, B. A. \}

"considerando que os sujeitos sociais são portadores de valores e do ethos de seu tempo." (2007, p. 45).

Pereira (2011) define "política social" como sendo uma categoria acadêmica e política, que não se limita em conhecer e interpretar o mundo real, mas atua com vistas a transformá-lo. Alertando para as inúmeras leituras sobre política social, especialmente em tempos neoliberais, Pereira (2011, p. 172-173) explica que, no Brasil, há apenas um termo para definições diferentes do agir no Estado, e que, portanto, deve-se atentar a essas diferenciações entendendo que a definição de "política social" refere-se à "política de ação", que busca responder as "necessidades sociais cuja resolução ultrapassa a iniciativa privada, individual e espontânea, e requer deliberada decisão coletiva regida por princípios de justiça social". A política social está "inextricavelmente relacionada ao Estado, governo, políticas (no sentido de politics e polity) e aos movimentos da sociedade". E, portanto, "ao contemplar todas as forças e agentes sociais, comprometendo o Estado, a política social se afigura uma política pública, isto é, um tipo, dentre outros, de políticas públicas".

A existência de políticas sociais está associada à constituição da sociedade burguesa, ou seja, do específico modo capitalista de produzir e reproduzir-se. Boschetti e Behring (2007) localizam seu surgimento no período de reconhecimento da inerência da questão social às relações no modo de produção capitalista. Isto se dá concomitantemente ao início de organização da classe trabalhadora, momento em que assumem papel político revolucionário e de resistência à exploração capitalista.

A partir deste período, a política social se estruturou institucionalmente. Passou por experiências de Bem-estar, como naqueles países que vivenciaram o "Welfare State", implantado ao final do século XIX e definido por Pereira (2011, p. 23) como "moderno modelo estatal de intervenção na economia que, ao contrário do modelo liberal que o antecedeu, fortaleceu e expandiu o setor público e implantou e geriu sistemas de proteção social". Foi traduzido para "Estado de Bem Estar Social" somente no pós-Segunda Guerra na Europa.

Desta forma, a política social se esfacelou após emergência do neoliberalismo, reestruturando-se novamente no início do século XXI. A diminuição da "intensidade protetora do Estado, no debilitamento do universalismo e no auge do privatismo, [vem] trazendo para o centro do processo de gestão do bem-estar contemporâneo arranjos tradicionais" que se vestem de novos (PEREIRA, 2011, p. 201-202). Seu objetivo é uma coesão social através de pactos corporativos pautados no princípio da subsidiaridade, que incorrem em um apelo voluntarista e baseado na lógica compensatória (PEREIRA, 2011). As classes dominantes "nunca tiveram compromissos democráticos e redistributivos, tem-se um cenário complexo para as lutas em defesa dos direitos de cidadania, que envolvem a constituição da política social." (BOSCHETTI; BEHRING, 2007, p. 79). 


\section{hevista pll pavtg}

\} HOMONACIONALISMO E CIDADANIA LGBT - IRINEU, B. A. \}

Fraser (2007, p. 295) relata sobre a "Segunda Onda" do feminismo. Este período se articula com o momento de reestruturação da política social na Europa e acreditamos que seja importante para relacionar política social com a concepção dos movimentos de luta por direitos sexuais. $\mathrm{Na}$ década de 1960, a juventude radical ocupou as ruas, "primeiro para se opor à segregação racial e à Guerra do Vietnã." Posteriormente, para discutir:

Características centrais da modernidade capitalista que a social-democracia tinha naturalizado até então: repressão sexual, sexismo e heteronormatividade; materialismo, cultura corporativa e a 'ética do sucesso'; consumismo, burocracia e 'controle social'. Rompendo as rotinas políticas normalizadas da era anterior, novos atores sociais formaram novos movimentos sociais, com a segunda onda do feminismo entre os mais visionários.

O feminismo desse período, ao lado de outros movimentos sociais, desafiou as desigualdades de gênero na social-democracia (regime focado na redistribuição socioeconômica, mas com intuito de movimentar a economia). Fraser (2007, p. 295) relembra que, ao questionar e problematizar o paternalismo do Estado de Bem-estar Social e a família burguesa, "os feminismos expuseram o profundo androcentrismo da sociedade capitalista. Politizando o 'pessoal', expandiram as fronteiras de contestação para além da redistribuição socioeconômica - para incluir trabalho doméstico, a sexualidade e a reprodução".

Com os questionamentos quanto ao dirigismo keynesiano às demandas por reconhecimento, levadas pelos movimentos de contracultura, e com a queda do comunismo no Leste europeu, as estratégias ideológicas do livre-mercado ressurgiram e se recriaram no neoliberalismo. Fraser (2007, p. 297) critica, a partir desse contexto de emergência do neoliberalismo, as táticas adotadas pelo feminismo do inicio da Terceira Onda que, segundo ela, estavam "efetivamente encantadas pela política de reconhecimento". Sem intuito, "direcionamos a teoria feminista para canais culturalistas precisamente quando as circunstâncias requeriam atenção redobrada a políticas de redistribuição".

Fraser (2007) reflete sobre o enigma da igualdade e a cilada da diferença, levando-nos a ponderar sobre qual prisma se deve atuar: por reconhecimento das identidades e da diferença a partir de uma transformação cultural ou por uma redistribuição socioeconômica através de um novo modelo econômico? Fraser (2007) concluirá que as duas dimensões não podem estar indissociadas. Alerta, ainda, para um mau enquadramento, combatido pelas feministas que vêm se dedicando a uma atuação trans-

\footnotetext{
"A "Primeira Onda" do feminismo relacionava-se com demandas advindas do segmento de mulheres brancas de classe média, acesso da mulher à educação e direito ao voto. A "Segunda Onda" tem a influência da contracultura, preocupando-se também com avanço na produção do conhecimento. Com seu desdobramento, especialmente através da influência do movimento negro e das lésbicas, surge a "Terceira Onda do feminismo".
} 


\section{hevistg all paUtg}

\} HOMONACIONALISMO E CIDADANIA LGBT - IRINEU, B. A. \}

nacional, no sentido de ampliar críticas aos regimes territoriais que conformam as desigualdades sociais em um sentido global.

Para a autora, este mau enquadramento se resolveria incluindo uma terceira dimensão, a partir do reconhecimento, da redistribuição e da representação - sendo esta entendida com o direito à voz política em pé de igualdade a todas as mulheres, justiça de gênero em um espectro transnacional - em uma integração equilibrada.

O caminho que Fraser (2007) relatou estar em curso no feminismo é entendido, por nós, como um investimento a ser feito no campo da organização das lutas LGBT. Consideramos que as reflexões sobre "homonacionalismo ${ }^{3 "}$ ou "nacionalismos sexuais", que faremos ao final, podem somar na constituição de uma estratégia transnacional que vá além do dilema da igualdade/diferença, ainda pouco amadurecida no espaço das lutas LGBT no Brasil.

\section{Homonacionalismo e as demandas por direitos humanos e "cidadania LGBT" no Brasil}

Como referenciamos anteriormente, as políticas sociais são produto de um movimento de correlação de forças onde surge uma demanda, havendo a necessidade de luta e mobilização para a percepção desta e o surgimento de uma ação que a contemple. Essa resposta é negociada através de consenso para o outorgamento dessa demanda (PASTORINI, 1997). Este movimento não se dá de maneira unilinear, mas sim de forma processual e dialética.

Nesta perspectiva, as intervenções e posições governamentais em relação aos direitos da população LGBT devem ser compreendidas como resultantes de processos de hegemonia, numa dinâmica intrincada de visibilidade-invisibilidade e concessão-conquista. Ou seja, uma relação onde as/os envolvidas/os na luta e implicadas/os nessa negociação conquistem e concedam ao mesmo tempo.

No Brasil, o então denominado movimento homossexual ${ }^{4}$ organiza suas primeiras ações no final da década de 1970, embora já existissem, desde os anos 1950, atos individuais de politização das identidades gay e lésbica em locais de lazer (GREEN, 2007). Contudo, é nas décadas de 1980 e 1990 que a invisibilidade homossexual começa a ser desvelada, especialmente com o advento da epidemia de HIV/aids.

O diálogo com o poder público torna-se inevitável nesse período devido ao estigma da "peste gay", como a aids foi chamada em seu sur-

\footnotetext{
${ }^{3}$ Puar (2007) conceitua homonacionalismo como a apropriação das questões de gênero e sexualidade para mascarar crimes de guerra, tais como massacres e ocupações coloniais. Isto mais especificamente no entrave Israel e Palestina, no qual o incentivo ao turismo gay friendly serve para ocultar o genocídio palestino por Israel. [tradução própria].
} 


\section{hevista pll pavtg}

\} HOMONACIONALISMO E CIDADANIA LGBT - IRINEU, B. A. \}

gimento. A reabertura política e o processo de redemocratização do Brasil foram fundamentais para expansão da produção de conhecimento sobre gênero e sexualidade, em uma perspectiva distinta das ciências "psi". Iniciase, assim, um processo de articulação entre os diversos sujeitos vinculados às lutas por direitos sexuais, que culminará em estratégias para interferir na formulação das demandas por políticas públicas.

As áreas da saúde e da educação formal tornaram-se o foco dos movimentos feministas e LGBT. A justificativa do primeiro tem referência na epidemia de HIV/aids; do segundo, na possibilidade de atingir as relações de preconceito e discriminação desde o primeiro momento de socialização (FACCHINI; DANILIUKAS; PILLON, 2013).

O período da Constituinte marcou as primeiras tentativas de diálogo do movimento homossexual com o poder Legislativo. As análises de Câmara (2000) relembram a tentativa de inserção do termo "discriminação por orientação sexual" no artigo $5^{\circ}$ do texto constitucional, que foi vetado por deputados da bancada religiosa. Sobre essa questão, o Deputado Salatiel Carvalho afirmou: "os evangélicos não querem que os homossexuais tenham igualdade de direitos porque a maioria da sociedade não quer". Acrescentando: "[...] os direitos que eles [homossexuais] entendem como seus podem ser prejudiciais à formação da própria família, podem ser prejudiciais, inclusive, à formação e à educação." (CÂMARA, 2000, p. 129). Esse episódio de insucesso do movimento LGBT brasileiro é o primeiro na tentativa de pautar o direito à não discriminação por orientação sexual.

Nos anos 1990, o Projeto de Lei no 1151/95, de autoria da Deputada Marta Suplicy, que previa a parceria civil registrada (PCR) entre pessoas do mesmo sexo, visando à proteção dos direitos à propriedade, usufruto de bens caso o parceiro viesse a falecer, pensão e plano de saúde, entre outras, atravessou o novo século sem aprovação (BRASIL, 1995). Recentemente, entrou para essa lista o Projeto de Lei 122/2006, que criminaliza a discriminação às pessoas LGBT (BRASIL, 2006). Criticado com rigor pela Frente Parlamentar Cristã, foi reformulado diversas vezes até ser reprovado no ano de 2013.

Ainda no Legislativo, a Frente Parlamentar Mista pela Livre Expressão Sexual (FPMLES) foi criada em 2003, sendo integrada por 196 parlamentares e tendo 216 parlamentares ao final de 2010. No ano de 2011, com início da 54aㅡ legislatura, ela foi rearticulada com o nome de Frente Parlamentar Mista pela Cidadania LGBT (FPMCLGBT), com 175 parlamentares.

É possível fazer um paralelo quantitativo com o número de parlamentares que integram atualmente a Frente Parlamentar Mista em Defesa da Vida e Contra o Aborto, que somam 205 parlamentares; ou que integram

\footnotetext{
${ }^{4}$ As categorias homossexual e gay foram utilizada como universal, para identificar todas as pessoas que tinham relações sexuais com outras do mesmo sexo. Contudo, os termos estavam carregados da hegemonia masculina questionadas a partir do aumento da participação das lésbicas e a emergência de uma identidade trans. (MELLO, 2010; FACCHINI e SIMÕES, 2009).
} 


\section{ReVistg all paUtg}

\} HOMONACIONALISMO E CIDADANIA LGBT - IRINEU, B. A. \}

a Frente Parlamentar da Família e Apoio à Vida, que são 228 parlamentares. Ressalta-se que, no mesmo ano de criação da FPMLES, também foi criada a Frente Parlamentar Evangélica ${ }^{5}$. De acordo com levantamento realizado em meados da 54a legislatura, em 2013, pela Câmara Legislativa, caso fosse uma agremiação partidária, esta frente seria a terceira maior bancada de deputados, atrás somente do PMDB e do PT (BRASIL, 2013a).

Percebe-se que, quando os grupos que se vinculam aos valores tradicionais aumentam sua capacidade de incidir nas decisões políticas, evidencia-se um regime de defesa do modelo exclusivo de família (antihomossexual) e de uma perspectiva de controle da autonomia do sujeito e punição do prazer, sobrepondo-se às demandas por reconhecimento dos direitos humanos (NATIVIDADE; OLIVEIRA, 2007).

Com essas recusas no Legislativo e com o Judiciário dependendo de iniciativas individuais, Mello et al. (2010) consideram que a única alternativa, ao movimento LGBT, acabou sendo o Executivo. A intensificação das investidas no Executivo fez com que o movimento atuasse influenciando diretamente os sistemas de educação, segurança e saúde, aproximando-se também das universidades, de outros movimentos sociais e dos partidos políticos.

Durante o Governo Lula (2003-2010) a relação com o Poder Executivo rende as primeiras iniciativas em âmbito federal, e tendo continuidade no atual Governo Dilma. As lutas promovidas pelo movimento LGBT no Brasil oportunizaram, em articulação com o Estado, ações governamentais como o Programa Brasil sem Homofobia (2004), vinculado à Secretaria Especial de Direitos Humanos (SEDH). Ele originou, posteriormente, a Coordenação Geral de Promoção dos Direitos LGBT (2009) e o Conselho Nacional de Combate à Discriminação LGBT (2011), responsáveis pela execução e monitoramento do Plano Nacional de Promoção dos Direitos e Cidadania LGBT (2009), produto da I Conferência Nacional de Políticas Públicas e Direitos Humanos LGBT (2008).

A criação do BSH iniciou ações específicas, implicando em uma inserção expressiva, se considerarmos a existência reduzida de iniciativas da temática na agenda política brasileira antes de sua criação.

Acrescenta-se também a realização da I e II Conferência Nacional de Políticas Públicas e Direitos Humanos LGBT, em 2008/2011, a criação da Política Nacional de Saúde Integral LGBT pelo Ministério da Saúde, em 2010, a criação do Sistema Nacional de Promoção de Direitos e Enfrentamento à Violência contra LGBT, em 2013, e o reconhecimento da diversidade de "condições sexuais" no âmbito do Plano de Política Criminal e Penitenciária, em 2011. Este último gerou a Resolução Conjunta noํ01/

\footnotetext{
${ }^{5}$ O deputado do PRTB, Antônio Bulhões, em um pronunciamento em 03/03/2014, afirmou sobre os objetivos da Frente Parlamentar Evangélica: "Por óbvio, a Frente Parlamentar Evangélica defende os interesses das igrejas evangélicas, mas não apenas isso. Para além do credo religioso, luta pela preservação dos valores e princípios morais da sociedade, de modo a resguardar os cidadãos também quanto aos direitos estabelecidos em nossa Carta Magna." (grifos nossos).
} 


\section{hevista pll pavtg}

\} HOMONACIONALISMO E CIDADANIA LGBT - IRINEU, B. A. \}

2014, entre o Conselho Nacional de Política Criminal e Penitenciária (CNPCP) e o Conselho Nacional de Combate à Discriminação - LGBT (CNDC), estabelecendo parâmetros de acolhimento de LGBT em privação de liberdade.

Todavia, apesar dessas iniciativas, demonstra-se o quanto gênero e sexualidade estão envoltos num "pânico moral" que estas políticas ainda não foram suficientes para dissolver. Para Miskolci (2007, p. 103) a definição de pânico moral se relaciona com a existência de "mecanismos de resistência e controle da transformação societária", que surgem a partir do "medo social com relação às mudanças, especialmente as percebidas como repentinas e, talvez por isso mesmo, ameaçadora".

O cenário indica avanços e retrocessos na agenda anti-homofobia, como o veto ao "Kit Escola sem Homofobia", em 2011, sustentado pela declaração da Presidenta Dilma de que em seu governo não faria "propaganda de opções sexuais". São exemplos também a retirada do termo "gênero" do Plano Nacional de Educação (PNE), neste ano de 2014, a propositura do Estatuto do Nascituro ${ }^{6}$, que aguarda para ser votado, e o Projeto de Decreto-lei que ficou conhecido como Projeto da "Cura Gay",, arquivado por decisão do próprio autor devido às manifestações de junho em 2013.

O recrudescimento do conservadorismo, frente às demandas dos movimentos que lutam pela inserção da pauta dos direitos sexuais e reprodutivos, caminha paralelo às conquistas destes grupos no campo da cidadania.

Esses caminhos podem ser observados pelo fato de que, ao mesmo tempo em que houve vetos e proposituras violadoras de direitos humanos, no âmbito do Judiciário recentes conquistas ocorreram no país. É exemplo disso a decisão do Conselho Nacional de Justiça (CNJ), que em maio de 2013 aprovou resolução proposta pelo ministro do Supremo Tribunal Federal (STF), Joaquim Barbosa, obrigando os cartórios de todo o país a registrarem o casamento civil entre pessoas do mesmo sexo. Essa resolução baseou-se em decisões proferidas pelo STF e pelo Superior Tribunal de Justiça (STJ) no ano de 2011.

Isto demonstra o processo de "judicialização" de direitos a que temos nos submetido, cujos efeitos recriam entendimentos falaciosos sobre uma cidadania LGBT plena, já que essas "conquistas" estão condicionadas a instrumentos jurídicos frágeis, que podem ser revogados e retirados a qualquer momento. Sobre ele, Vianna, Burgos e Salles (2007, p. 41) dizem que:

\footnotetext{
${ }^{6}$ Projeto de Lei (PL) 478/2007, em tramitação, com autoria de Luiz Bassuma (PEN) e Miguel Martini (PHS). O Estatuto visa criminalizar o aborto e " a apologia de aborto". Ele ficou conhecido como "bolsa Estupro", pois em seu artigo 13, prevê que o nascituro concebido em decorrência de estupro terá assegurada pensão alimentícia pelo Estado (BRASIL, 2007).

${ }^{7}$ O Projeto de Decreto Legislativo (PDC) 234/2011, de autoria do Deputado João Campos (PSDB), sugeria a extinção de dois trechos de uma resolução de 1999 do Conselho Federal de Psicologia (CFP), que tratam da não colaboração com eventos e serviços para tratamento e cura das homossexualidades e com pronunciamentos públicos para reforçar os preconceitos sociais em torna da homossexualidade como desordem psíquica.
} 


\section{Aevistg all paUtg}

\} HOMONACIONALISMO E CIDADANIA LGBT - IRINEU, B. A. \}

a invasão do direito sobre o social avança na regulação dos setores mais vulneráveis, em um claro processo de substituição do Estado e dos recursos institucionais classicamente republicanos pelo judiciário, visando a dar cobertura à criança e ao adolescente, ao idoso e aos portadores de deficiência física. O juiz torna-se protagonista direto da questão social. Sem política, sem partidos ou uma vida social organizada, o cidadão volta-se para ele, mobilizando o arsenal de recursos criado pelo legislador a fim de lhe proporcionar vias alternativas para a defesa e eventuais conquistas de direitos. A nova arquitetura institucional adquire seu contorno mais forte com o exercício do controle da constitucionalidade das leis e do processo eleitoral por parte do judiciário, submetendo o poder soberano às leis que ele mesmo outorgou.

Embora avaliemos como pedagógicos os significados destas decisões do STJ e STF, é necessário termos dimensão desse processo de "judicialização". Algumas estratégias desenvolvidas por determinados segmentos do movimento LGBT, como o "abraço ao STF" em agradecimento à decisão favorável à união civil em 2011, realizado na II Marcha Nacional de Combate à Homofobia, corroboram com o que mencionamos ser o "fetiche da condição de cidadão." (LESSA, 2006).

Para compreender a complexidade dessas estratégias, é preciso problematizar a perspectiva de cidadania que este movimento social vem negociando com o Estado. Contudo, é necessário lembrar que os movimentos sociais são compostos de sujeitos e grupos heterogêneos vinculados a distintos projetos de sociedade em disputa na arena pública (MONTAÑO; DURIGHETO, 2011). É importante, ainda, recordar que o movimento LGBT no Brasil passou por um processo de onguização no final da década de 1980 e início de 1990, justificado na necessidade de buscar recursos financeiros para desenvolver ações de combate à aids (FACHINNI; SIMÕES, 2009).

Ao final dos anos 1990 e início dos anos 2000, o surgimento de redes e coletivos não onguizados com agendas de combate ao racismo, ao machismo e à transfobia, protagonizados por lésbicas, travestis e transexuais, dão novos contornos ao movimento LGBT brasileiro. As paradas do orgulho iniciadas em 1997, na Região Sudeste e Sul do país, hoje ocorrem em todos os estados e se configura na maior manifestação pública de rua. Essa expansão também possui relação de "negociações e tensões" com o mercado (boates, bares, sites e empresas) e com o crescimento do turismo gay mundial (FACCHINI; SIMÕES, 2009).

Nesta conjuntura histórica, o termo cidadania homossexual ou cidadania LGBT está presente em documentos, ações e iniciativas do movimento social e do poder público: Marcha pela Cidadania Homossexual (1997); Seminário Direitos Humanos e Cidadania Homossexual (1999), realizado na Câmara Federal; edital lançado pela Secretaria de Direitos Humanos (SDH/PR) para apoio à criação de Núcleo de Referência em Cidadania Homossexual e Direitos Humanos nas universidades públicas 


\section{hevista pll pavtg}

\} HOMONACIONALISMO E CIDADANIA LGBT - IRINEU, B. A. \}

(2006); Disque Cidadania Homossexual (2010) - lançado como Disque Defesa Homossexual, no Rio de Janeiro em 1999, e em funcionamento com a nomenclatura "cidadania" no Rio de Janeiro (2010) e no Piauí (2014); Plano Nacional de Promoção da Cidadania e Direitos Humanos LGBT (2009), lançado pela SDH/PR; Coordenadoria de Direitos Humanos e Cidadania LGBT, órgãos de competência municipal ou estadual que executam as políticas para população LGBT, cuja nomenclatura inclui a palavra "cidadania", em Olinda (PE) (2013) e João Pessoa (PB) (2012); Curso de Formação "A conquista da cidadania LGBT - a política de diversidade sexual no Estado de São Paulo", destinado a servidores públicos municipais e estaduais de São Paulo (SP), realizado pela Coordenadoria de Diversidade Sexual de São Paulo - CADS (2012); Prêmio de Direitos Humanos e Cidadania LGBT de Belo Horizonte (MG) (2004), que está em sua décima edição anual e é realizado às vésperas da parada do orgulho.

Diante desse levantamento e considerando o processo de "estadania" brasileiro, já referido no início deste texto, pode-se inferir que a população LGBT, ao longo destes 35 anos de luta organizada, tem passado por um processo de "SIDAdanização", nos termos de Pelúcio (2009), utilizando a sigla Sida (Síndrome da Imunodeficiência Adquirida), que tem o mesmo significado da aids. É um processo de conquista da cidadania obtido através do sistema preventivo oficial de DST/aids.

Há, em trânsito, outra perspectiva de cidadania para esta população, delineada principalmente via políticas públicas com objetivos que permeiam tanto a denúncia das violências e discriminações motivadas pela orientação sexual e/ou identidade de gênero, quanto ações de afirmação de identidades e ampla divulgação de informação sobre direitos humanos LGBT.

Os documentos que balizam a política nacional LGBT também oferecem elementos para essa análise. O programa BSH (2004) atrelou a cidadania em seu próprio título, referenciando a compreensão de promoção da "cidadania homossexual" através de: fortalecimento do exercício da cidadania no Brasil; profissionalização das travestis; equiparação de direitos e combate à violência e discriminação homofóbica; apoio a projetos de fortalecimento de instituições públicas e não governamentais; proposição de mecanismos normativos para cidadania e permanência de estrangeiros companheiros de homossexuais no Brasil e apoio à promoção de ações pelo poder público (CONSELHO NACIONAL DE COMBATE À DISCRIMINAÇÃO, 2004).

$\mathrm{O}$ texto do $\mathrm{BSH}$ afirma que os efeitos da luta por cidadania geraram como frutos as resoluções do Conselho Federal de Medicina (CFM), em 1989, e do Conselho Federal de Psicologia (CFP), que retiram a homossexualidade do roll de doenças.

No Plano Nacional de Promoção da Cidadania e dos Direitos Humanos LGBT (2009), a "cidadania LGBT" está compreendida como objetivo central da formulação do plano, que afirma possuir diretrizes, pre- 


\section{hevistg all paUtg}

\} HOMONACIONALISMO E CIDADANIA LGBT - IRINEU, B. A. \}

ceitos éticos e políticos para "garantia dos direitos e exercício pleno da cidadania". Sua materialidade se daria através de: editais que beneficiem a valorização cultural LGBT e a promoção da cidadania LGBT; inclusão de conteúdos sobre "diversidade sexual" para conselheiros; inserção de temas sobre cidadania LGBT nos concursos de servidores públicos do governo federal; criação de um selo nacional para empresas que promovem a cidadania LGBT e realização bianual das conferências estaduais e nacional LGBT. (BRASIL, 2009).

O BSH e o Plano se diferenciam na sua concepção. Pode-se considerar o Plano mais tecnicamente assertivo nas estratégias, demonstrando o próprio processo de maturação técnica da política LGBT. Embora se reconheça essas alterações, é inegável que permanece enfocado no campo da denúncia, visibilidade/afirmação de identidades e formação política. O Conselho Nacional de Combate à Discriminação LGBT (CNDC), recriado em 2010 junto à SDH/PR, vinculado à participação social no monitoramento das políticas públicas, tem promovido uma compreensão de cidadania.

O Sistema Nacional de Enfrentamento à Violência contra população LGBT foi criado em 2013 com a finalidade de organizar e promover cidadania e direitos LGBT, por meio da criação de conselhos, planos e órgãos de gestão da política pública LGBT. Através do Pacto Nacional de Enfrentamento à Violência contra a população LGBT, envolve a assinatura de termo (pelo Estado), a criação de um comitê reunindo a sociedade civil organizada LGBT e um centro de promoção e defesa dos direitos LGBT. São equipamentos de acolhimento, atendimento e encaminhamento das demandas de violência e promoção de ações afirmativas.

O documento que institui o Sistema LGBT indica que ele tem a pretensão de promover equidade social através da cidadania e enfrentamento da violência (BRASIL, 2013b). São mencionados o Suas (Sistema Único de Assistência Social) e o SUS (Sistema Único de Saúde) como sendo suas bases de formulação política. Entretanto, há um distanciamento significativo destas duas políticas com o Sistema LGBT. Um dos fatores é que elas são políticas de Estado, garantidas legalmente e com dotação orçamentária, ao passo que o Sistema LGBT foi instituído por portaria e não possui uma dotação orçamentária explícita.

Desde a realização da II Conferência Nacional LGBT, em 2011, algumas entidades da sociedade civil têm utilizado o termo "tripé da cidadania LGBT" para descrever essa demanda formulada como prioritária no âmbito do Poder Executivo. No documento publicado pela SDH, em maio de 2013, intitulado "Cidadania LGBT: mapa de boas práticas, Brasil - União Europeia", há uma explicitação do que seria o "tripé":

O assim chamado 'tripé da cidadania LGBT' (uma Coordenadoria LGBT na estrutura do governo; um Plano LGBT governamental; e um Conselho LGBT para exercer o controle social sobre a formulação e exe- 
cução das políticas públicas específicas) foi completado no âmbito federal com a instituição em dezembro de 2010 do Conselho Nacional de Combate à Discriminação e Promoção dos Direitos de LGBT, um órgão colegiado de natureza consultiva e deliberativa, integrante da estrutura básica da SDH, contando com quinze representantes do Poder Público Federal. (BRASIL, 2013c, p. 26 \% grifos nossos).

Portanto, neste caso, a cidadania LGBT estaria vinculada novamente ao campo das políticas públicas, circunscrevendo-se em reivindicações por liberdades e autonomia civis e pelo "reconhecimento" da diferença, na concepção de Fraser (2007). O que implica em utilizar a cidadania como estratégia política, que "permitiria pensar projetos de mudança social que não redundem na transformação econômica nem se concentra na tomada do poder político", como avaliaram Durigheto e Montaño (2011, p. 335) em debate crítico frente ao enfoque institucional dos movimentos sociais de Dagnino (apud MONTAÑO; DURIGUETHO, 2011).

Essa leitura não compreende apenas a realidade brasileira. Em uma análise sobre as lutas LGBT em Portugal, Oliveira (2013) descreve a distinção entre heterossexuais e homossexuais mesmo após aprovação do casamento homossexual no país. Dá como exemplo o fato de que, para pessoas LGBT, passa a existir a possibilidade do casamento, mas não da adoção. Com esse argumento ele nomeia estas conquistas de incompletas, no campo da cidadania sexual de "cidadania de consolação", rearticulando a crítica ao "pink money" com a política de intervenção social e econômica mínima - neoliberalismo.

Shulmann (2013, p. 4) assinala que, na medida em que alguns direitos gays foram sendo aprovados nos países, algumas pessoas da comunidade LGBT tiveram "acesso ao aparelho de estado, à polícia e aos poderes de punição e execução - contra outros elementos da comunidade LGBT que ainda não podiam acessar essas forças.". Isto implicou em uma comunidade onde todas/os estavam na ilegalidade ao transitar para outra, na qual algumas pessoas LGBT passam a ter o poder do grupo dominante em sociedades profundamente injustas.

Schulmman (2013) percebe como sendo três as principais arenas onde o acesso à punição do Estado é garantido a pessoas LGBT: a criminalização do HIV, a política LGBT pró-família e a cidadania homossexual. Como exemplo desta última ela cita que o repúdio à "don't ask, don't tell" (em português, "não pergunte, não fale", termo utilizado para referir à política de restrição a homossexuais e bissexuais declarados no exército dos Estados Unidos) levou as pessoas LGBT à "cidadania" - direito de servir as forças armadas sendo assumidamente gay "em troca da participação em guerras imorais e ilegais contra muçulmanos no Iraque e no Afeganistão." (SHULMANN, 2013, p. 5). Ou seja, as pessoas LGBT obtêm cidadania plena a partir de uma cooperação com o Estado para punir, excluir e até matar, encorajadas por ele: "Las raíces culturales del nacionalismo están en esa 


\section{hevistg all paUtg}

\} HOMONACIONALISMO E CIDADANIA LGBT - IRINEU, B. A. \}

fraternidad y esta libertad imaginada que justifican incluso que se mate y se esté dispuesto a morir por la nación". (CURIEL, 2012, p. 28).

Estas situações são englobadas por Puar (2013, p. 336) em seu conceito de "homonacionalismo", problematizando a compreensão de como as complexidades de "aceitação" e "tolerância" à população LGBT e suas demandas se "tornaram um barômetro pelo qual o direito e a capacidade de soberania nacional são avaliados" e considerados democráticos. Como exemplo, os países Israel e Palestina. O primeiro é considerado uma nação democraticamente aberta à homossexualidade, sendo eleito um polo de turismo gay nos últimos anos. Já a Palestina, que não possui essa abertura no campo dos direitos LGBT, tem sido profundamente devastada pelos ataques antidemocráticos de Israel, intensificados nos anos 2000.

Curiel (2012) compreende a nação como uma comunidade imaginada que foi naturalizada enquanto campo de constituição de valores morais e projetos de sociabilidade - a nacionalidade tornou-se, assim, um direito e se ancorou em um modelo familista, racista, sexista e homofóbico. Quando o regime da heterossexualidade atua demarcando direitos, a cidadania se vê limitada. Neste sentido, quanto à política pró-família LGBT ou em uma tentativa de tradução livre para o contexto local \% "política da família homoafetiva" -, podemos considerar a recente aprovação do matrimônio igualitário no Uruguai como um exemplo mais próximo de nossa realidade.

Sempol (2013) aponta, em diálogo com Puar (2007), que o nacionalismo detém em seu discurso uma política de identificação muito forte, que envolve não apenas práticas sexuais, mas também a promoção de identidades heterossexistas. Embora considere a aprovação do matrimônio igualitário uma afronta à norma heterossexual, ele acredita que é uma estratégia de "normalização democrática".

Destarte, agregando a crítica ao homonacionalismo, parece-nos viável articular com um exemplo local referente às eleições deste ano de 2014. Na Internet e nos programas de televisão, pude observar dois elementos que podemos confrontar: o primeiro envolve os conhecidos "memes", que são frases vinculadas a imagens. Este foi divulgado principalmente na rede social Facebook, referindo-se ao fato de o Governo PT não fazer uso de empréstimos do Fundo Monetário Internacional (FMI), desde Lula até Dilma Roussef; e, além de não pedir empréstimos, criando um grupo político de cooperação, autônomo aos Estados Unidos, o Brics (Brasil, Rússia, Índia, China e África do Sul). A imagem foi compartilhada por diversos ativistas e pesquisadores/as LGBT e feministas com quem me relaciono nesta rede. Chamou-me a atenção a estratégia de engrandecimento de uma alternativa capitalista e desenvolvimentista a que estavam lançando mão, além de "lavar de rosa" o fato de que a Rússia, principal articuladora do Brics, desenvolve uma política do armário severamente restritiva à população LGBT. 


\section{hevista pll pavtg}

\} HOMONACIONALISMO E CIDADANIA LGBT - IRINEU, B. A. \}

O segundo elemento diz respeito a Dilma ter explicitado, pela primeira vez, ser favorável à "criminalização da homofobia". Isto gerou uma comoção por parte significativa do movimento LGBT, capaz de apagar a declaração que ela fez no período de veto do "Kit Escola sem Homofobia" e a questão de ser vista como uma guinada à esquerda. Há, nisso, uma grande conexão com fato de que hoje existe uma grande mobilização de setores conservadores do mundo das finanças e liberais republicanos apoiando ações LGBT, porque os direitos desta população estão incorporados à agenda e à geopolítica da direita. Não é a adesão a bandeiras da união civil que vão localizar os projetos de sociedade em disputa como sendo de "esquerda" ou "progressista", mas sim a explícita inserção em um campo de luta pela ruptura com o capitalismo.

Exemplifiquei com os elementos envolvendo a candidata Dilma, mas também podemos usar como exemplo tanto a candidatura de Aécio Neves (PSDB) quanto a de Marina Silva (PSB/Rede), que apresentaram em seu plano de governo propostas à comunidade LGBT. Todavia, foram as candidaturas de Luciana Genro (Psol) e Eduardo Jorge (PV) que levaram a público o debate sobre homofobia e aborto. Novamente uma comprovação de que as demandas por cidadania LGBT foram absorvidas pelas diversas tendências políticas.

Houve espanto, por parte de alguns militantes LGBT nas redes sociais, com o apoio do PV a Aécio Neves, no $2^{\circ}$ turno, como se a vinculação do candidato às pautas feministas e LGBT Ihe conferissem um lugar vitalício à esquerda. Os projetos societários estão em disputa e aquelas demandas que se restringem à cidadania liberal também estarão em disputa.

\section{Conclusão}

Buscou-se, neste texto, levantar críticas ao conceito de "cidadania" que vem sendo demandado pelo movimento LGBT no contexto brasileiro. O lugar de quem propõe essa problematização também se constitui no campo da luta por direitos sexuais, seja desenvolvendo uma militância específica no campo da universidade, atuando como pesquisadora em gênero e sexualidade seja exercendo minha lesbianidade no cotidiano. Esse sentido de imbricação nos fornece elementos para uma crítica do que viemos desenvolvendo na universidade, por exemplo.

Durante os anos de 2012, 2013 e 2014, nos dedicamos, enquanto pesquisadoras, a assessorar a formulação do Plano Estadual de Políticas Públicas e Direitos Humanos LGBT em Tocantins, a partir de uma cooperação técnica científica (sem destinação de qualquer recurso financeiro). Realizamos um processo longo de formação da equipe do órgão governamental e da sociedade civil que participava da Comissão de formulação do Plano. 


\section{ReVistg all paUtg}

\} HOMONACIONALISMO E CIDADANIA LGBT - IRINEU, B. A. \}

Em uma troca de gestão, por interesse do governador em lançar a candidatura de seu filho, um novo governador assumiu o poder. O Plano demorou quatro meses para ser publicado, sendo revogado após uma semana devido a pronunciamentos e solicitações da base do novo governador, feitos, entre outros, por dois deputados da bancada evangélica.

Tanto a primeira gestão quanto a segunda mantiveram a comissão como forma de conformar essa "cidadania limitada". Esses mesmos governos empenham uma política de negligenciamento junto às comunidades indígenas e possuem, em sua base de governo, figuras políticas sob a acusação de utilização de trabalho escravo em suas fazendas.

É preciso questionar: a que custo pretendemos negociar nossa "cidadania de consolação"? Vamos "lavar de rosa" o sangue de grupos étnicos, imigrantes e trabalhadores em condição de escravidão que estes governos nacionalistas têm derramado? Ou iremos construir uma alternativa anticapitalista que rompa com o homonacionalismo?

Prefiro acreditar que caminharemos para uma estratégia que reúna reconhecimento como justiça, redistribuição socioeconômica e representação em condições de paridade, como propôs Fraser (2007). Fazer oposição à ideologia assumida pela burguesia e ressignificar a cultura política torna-se essencial para o estabelecimento de uma relação dialética entre Estado e sociedade civil, projetando um futuro que supere as determinações neoliberais e promova a livre expressão sexual e de gênero. 


\section{Referências}

BEHRING, E; BOSCHETTI, I. S. Política social: fundamentos e história. São Paulo: Cortez. 2007.

BRASIL. Projeto de Lei 478/2007. Câmara Federal: Brasília. 2007. Disponível em: <http://www.camara.gov.br/proposicoesWeb/prop_mostrarinte gra? codteor $=718396 \&$ filename $=S B T+1+C S S F+\% 3 \mathrm{D} \% 3 \mathrm{E}+\mathrm{PL}+478 / 2007>$. Acesso em: 29 jun. 2014.

. Secretaria Especial de Direitos Humanos. Plano Nacional de Promoção da Cidadania e dos Direitos Humanos LGBT. Brasília. 2009.

. Câmara Federal. 2013a. Disponível em: <http://www.camara .leg.br>. Acesso em: 29 ago. 2014.

. Secretaria de Direitos Humanos (SDH). Sistema Nacional de Enfrentamento à Violência LGBT e Promoção dos Direitos. Brasília. 2013.

. Secretaria de Direitos Humanos (SDH). Portaria $n^{\circ}$ 766, que institui o Sistema Nacional de Promoção de Direitos e Enfrentamento à Violência Contra Lésbicas, Gays, Bissexuais, Travestis e Transexuais (LGBT) e dá outras providências. Brasília: SDH. 2013b.

. Secretaria de Direitos Humanos (SDH). Cidadania LGBT: mapa de boas práticas, Brasil - União Europeia. Brasília: SDH. 2013c.

BUTLER, J. Problemas de gênero: feminismo e subversão da identidade. Rio de Janeiro: Civilização Brasileira. 2008.

CÂMARA, C. Cidadania e orientação sexual: a trajetória do grupo Triângulo Rosa. Rio de Janeiro: Academia Avançada. 2000.

CARVALHO, J.M. Cidadania no Brasil: um longo caminho. Rio de Janeiro: Civilização Brasileira. 2008.

CHAUÍ, M. Cultura e democracia: o discurso em duas falas. São Paulo: Moderna. 2007.

CONSELHO NACIONAL DE COMBATE À DISCRIMINAÇÃO. Brasil sem homofobia: programa de combate à violência e à discriminação contra LGBT e promoção da cidadania homossexual. Brasília: Ministério da Saúde. 2004.

CORRÊA, S. Cruzando a linha vermelha: questões não resolvidas no debate sobre direitos sexuais. Horizontes Antropológicos, Porto Alegre, ano 12, n. 26, jul./dez. 2006.

COUTINHO, C. N. Notas sobre cidadania e modernidade. Praia Vermelha: estudos de política e teoria social, Rio de Janeiro, v. 1, n. 1. 1997. 


\section{ReVistg all paUtg}

\} HOMONACIONALISMO E CIDADANIA LGBT - IRINEU, B. A. \}

CURIEL, O. El régimen heterosexual y la nación. Aportes del lesbianismo feminista a la antropologia. 2012. Disponível em: <http://biblioteca digital. univalle.edu.co/bitstream/10893/3501/1/art2.pdf >. Acesso em: 30 nov. 2012.

DECLARAÇÃO UNIVERSAL DOS DIREITOS HUMANOS. Adotada e proclamada pela resolução 217 A (III) da Assembléia Geral das Nações Unidas em 10 de dezembro de 1948. Disponível em: <http://www.direitoshuma nos.usp.br/index.php/Declara\%C3\%A7\%C3\%A3o-Universal-dos-DireitosHumanos/declaracao-universal-dos-direitos-humanos.html>. Acesso em: 01/10/2012.

FACCHINI, R; SIMÕES, J. A. Na trilha do arco-íris: do movimento homossexual ao LGBT. São Paulo: Perseu Abramo. 2009.

FACCHINI, R.; DANILIUKAS, M.; PILLON, A.C.; Políticas sexuais e produção de conhecimento no Brasil: situando estudos sobre sexualidade e suas conexões. Revista de Ciências Sociais, Fortaleza, v. 44, n. 1. 2013.

FORTI, V. Direitos humanos e serviço social: notas para o debate. O social em questão, Rio de Janeiro, ano XV, n. 28. 2012.

FRASER, N. Mapeando a imaginação feminista: da redistribuição ao reconhecimento e à representação. Revista Estudos Feministas, Florianópolis, v. 15, n. 2. 2007 a.

. Reconhecimento sem ética? Lua Nova: Revista de Cultura e Política, São Paulo, n. 70. 2007b.

GREEN, J. Além do carnaval: a homossexualidade masculina no Brasil. São Paulo: Loyola. 2007.

IAMAMOTO, M. V. Serviço Social em tempo de capital fetiche: capital financeiro, trabalho e questão social. São Paulo: Cortez. 2009.

LESSA, S. E. do C. O Estado, a cidadania e o fetiche da condição de cidadão: problematizando categorias. Revista Ágora: políticas públicas e serviço social. n. 4, jul. 2006.

MASCARO, A. Estado e forma política. São Paulo: Boitempo. 2013.

MELLO, L. et al. Políticas públicas para população LGBT no Brasil: um mapeamento crítico preliminar. Goiás: Ser-Tão. 2010.

MISKOLCI, R. Pânicos morais e controle social - reflexões sobre o casamento gay. Cadernos Pagu, Campinas, n. 28. 2007.

. O desejo da nação: masculinidade e branquitude no Brasil de fins do XIX. São Paulo: Annablume. 2012.

MONTAÑO, C.; DURIGUETHO, M.L. Estado, classe e movimento social. São Paulo: Cortez. 2011. 


\section{hevista pll pavtg}

\} HOMONACIONALISMO E CIDADANIA LGBT - IRINEU, B. A. \}

NATIVIDADE, M; OLIVEIRA, L. Religião e intolerância à homossexualidade. In: SILVA, V. G. (Org.). Intolerância religiosa: impactos do neopentecostalismo no campo religioso afro-brasileiro. São Paulo: Edusp. 2007.

OLIVEIRA, J.M. Cidadania sexual sob suspeita: uma meditação sobre as fundações homonormativas e neo-liberais. Psicologia \& Sociedade, Belo Horizonte, v. 25, n. 1. 2013.

PASTORINI, A. Quem mexe os fios das políticas sociais? Avanços e limites da categoria concessão-conquista. Revista Serviço Social e Sociedade. São Paulo, n. 53. 1997.

PELÚCIO, L.M. Abjeção e desejo: uma etnografia travesti sobre o modelo preventivo de aids. São Paulo: Annablume. 2009.

PEREIRA, P.A.P. Política social: temas e questões. São Paulo: Cortez. 2011.

PIOVESAN, F. Direitos humanos globais, justiça internacional e o Brasil. 2014. Disponível em: <http://www.escolamp.org.br/ARQUIVOS/15_07. pdf>. Acesso em: 20 abr. 2014.

PUAR, J. Terrorist assemblages: homonationalism in queer times. Durham: Duke University Press. 2007.

Studies. 2013.

Rethinking homonationalism. International Journal Middle East

RIOS, R.R. Para um direito democrático da sexualidade. Horizontes antropológicos, Porto Alegre, ano 12, n. 26, jul./dez. 2006.

SCHULMMAN, S. Desafios do feminismo: amigos diante da Família, sociedade diante do Governo. 2013. Disponível em: <http://geofaust.wordpress. com/2013/09/29/fazendo-genero-sarah-schulman/>. Acesso em: 1 out. 2013.

SEMPOL, D. De los baños a la calle: historia del movimiento lésbico, gay y trans uruguayo (1984-2013). Montevideo: Debate. 2013.

VIANNA, L.W.; BURGOS, M.B.; SALLES, P.M. Dezessete anos de judicialização da política. Tempo Social, São Paulo, v. 19, n. 2, nov. 2007.

VIEIRA, L. Cidadania e globalização. Rio de Janeiro: Record. 2005. 